\title{
A Complex Network Theory for Cascading Failure Problem in an Interdependent Food Supply Chain Network
}

\author{
Yan $\mathrm{Yan}^{1}$ and Wei $\mathrm{Xu}^{1}$ \\ ${ }^{1}$ School of Management, Shenyang University of Technology, Shenyang, 110870, \\ P.R.CHINA \\ yanyan8262@126.com
}

\begin{abstract}
In complex network, security and resilience issue in a network is very important. The breakdown of whole network can be triggered by attack or failure of even only a single node. In this paper, the cascading failure issue in a food supply chain is addressed. In the food supply chain network, all the nodes are interconnected and interdependent. The tight coupling of nodes increases efficiency of food supply chain, however, the association relation between nodes may cause cascading failure of food network. Firstly, a Node Importance Evaluation Method (NIEM) is employed to analyze cascading failure characteristics in the food supply chain network. Then, the critical nodes which may cause cascading failure in the whole network are identified. Subsequently, a Node Importance Evaluation Method is proposed to protect these critical notes. Finally, cascading failure caused by largest connected component is tested using the largest workload tolerance parameter.
\end{abstract}

Keyword: cascading failure; food supply chain; vulnerable, interdependency

\section{Introduction}

There have been many exciting recent developments in understanding the topologies of many natural and artificial networks[1-3]. One problem is the security of these networks, i.e., how failures or attacks affect the integrity and operation of the networks has been of great interest[4-6]. Another important problem is to characterize the resilience of complex networks[7]. Costa found that substantial reinforcement of the resilience of complex networks can be achieved by the expansions[8].

An intuitive reasoning based on the load distribution would suggest that, for a complex network, the possibility of breakdown triggered by attack or failure of even only a single node cannot be ignored. Cascading failures can occur in many physical systems, such as in the Internet, electrical power grids, etc. A number of important aspects of cascading failures in complex networks have been discussed in the literature, including disturbances in power transmission systems, the origin of rare events, the effect of network growth, cascading failures triggered by intentional attacks, avalanche size distributions, and congestion instabilities[9-12]. Holme and Kim provided an in-depth analysis on the vertex/edge overload cascading breakdowns based on evolving networks, and suggest a method to avoid such avalanches[13].

How is it possible that a small initial shock, such as the congested of a node which may be has higher flow or maximum betweenness in supply chain systems, can trigger avalanches mechanisms affecting a considerable fraction of the network and collapsing a system[14]. In this paper, we focus on cascading failure of food supply chain network, calculate the weight of each node and relative size of largest connected component.

The food supply chain network is very complex and such a supply network transports flows or load. Nodes with large capacity can transport heavier flows. Each 
node, however, has a finite capacity. In order for a node to function properly, its flow must be less than the capacity at all times; otherwise, the node fails[15]. If a node fails, its flow will be directed to other links, causing a redistribution of flow in the network[16]. If the failing link carries a large amount of flow, the consequence could be serious because this amount of flow needs to be redistributed and it is possible that for some nodes, the new flow exceeds their capacities[17-20]. These nodes will then fail, causing further redistribution of flow, and so on. As a consequence, a large fraction of the network can be shutdown. For example in the year of 2000, a protest over fuel price increase, which disrupted fuel supply, cost United Kingdom $£ 250$ million a day as a result of the cascading impacts of fuel shortage. The key role to understand the dynamics of cascading failures is to identify important node contributes most to cascading failure.

We wish to quantify the efficiency of networks before and after cascading failure. To make amenable we focus on food supply chain networks and investigate cascading failures triggered by attack on a single node.

\section{Networks Structure}

We represent a food supply chain network as graphs $G=(V, E)$ where $V$ is a set of food supply process from agricultural production: harvest/slaughter, through primary production and/or manufacturing, to storage and distribution to retail sale or use in catering and consumer practice, and E is a set of edges. G is described by the $N \times N$ adjacency matrix $\left\{e_{i j}\right\}$.Define $N$ as the size of the network.

The process of food supply chain is shown as following Figure 1

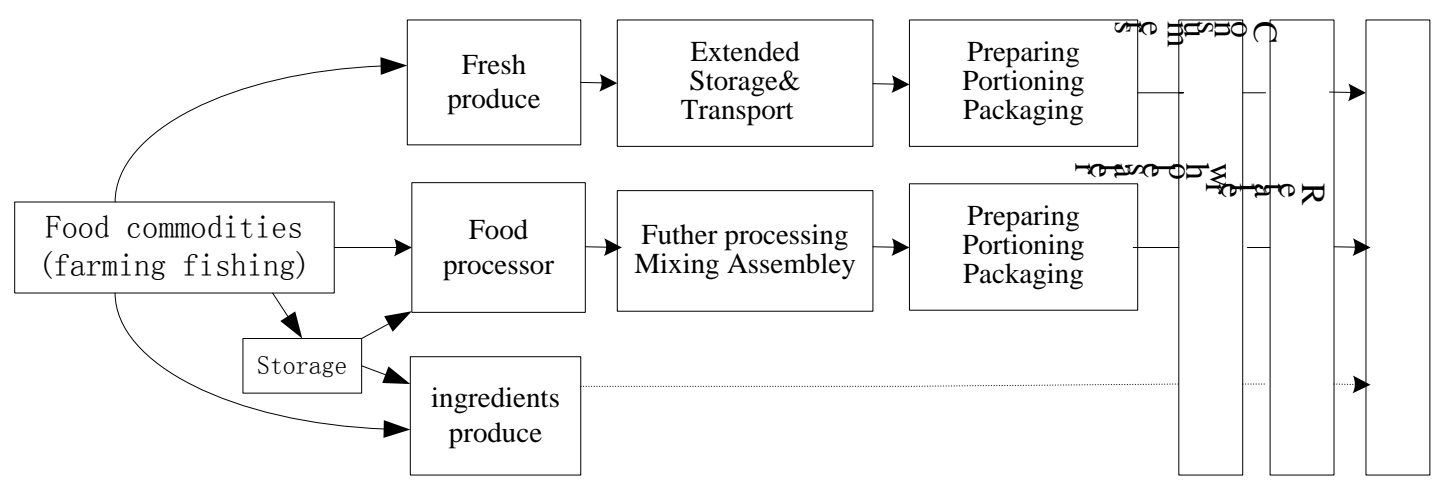

Figure 1. Food Supply Process Network

This has been a continued trend in technological innovations from foods leaving the farm and their handing up until reaching the end user the consumer. The food supply chain is divided into three parts: fresh produce; food processor; ingredients producer. Commodities of each part finally get to consumers through different procedures.

The "Efficiency" is always used to measure how efficiently information is exchanged in the network. Latora and Marchiori defined the global efficiency as follows:

$$
E(G)=\frac{1}{N(N-1)} \sum_{i \neq j \in G} \frac{1}{d_{i j}}
$$

Where $d_{i j}$ is the shortest path length between two generic nodes $\mathrm{i}$ and $\mathrm{j}$. In this paper we assume $d_{i j}$ is 1 in any pair of adjacent nodes. This is because each node reflects different processes of food supply chain. Its real distance is complicated so we 
do not consider it in this paper.

\section{Cascading Failure}

The load dynamics in food supply networks can be modeled, as follows. For a given network, suppose that at each time step one unit of the relative quantity, which can be food ,ect, is exchanged between every pair nodes and transported along the shortest path. To characterize the load distribution, the concept of betweenness is useful. The definition of betweeness was proposed by Freeman in 1977 for the first time. It counts the fraction of shortest paths going through a given node. More precisely, the betweeness of a node $\mathrm{v}$ is given by formula (1)

$$
C_{B}(v)=\sum_{s \neq v \neq t} \frac{\sigma_{s t}(v)}{\sigma_{s t}}
$$

where $\sigma_{s t}$ is the total number of shortest paths from node $s$ to node $t$ and $\sigma_{s t}(v)$ is the number of shortest paths from $s$ to $t$ going through $v$. Because node $v$ can not be $s$ or $t$, betweeness of endpoint of network may be 0 . It does not mean its load is 0 , the result only shows that they are not nodes with high importance. The capacity of a node is the maximum load that the node can handle. In manmade networks, the capacity is severely limited by cost. Thus it is natural to assume that the capacity $C_{k}$ of node k is proportional to its initial load $L_{k}(0)$, It can be shown as formula (2):

$$
C_{k}=L_{k}(0) \square(1+\alpha)
$$

where $L_{k}(0)$ is initial load of node $k$. The constant $\alpha \geq 0$ is the tolerance parameter. When all nodes are on, the network operates in a free-flow state insofar as $\alpha \geq 0$ (in this study we get $\alpha=0.3$ according to actual situation). But, the removal of nodes in general changes the distribution of shortest paths. The load at a particular node can then change. If it increases and becomes larger than the capacity, the node fails. Any failure leads to a new distribution of load and, as a result, subsequent failures can occur. The failures can stop without affecting too much of the connectivity of the network but it can also propagate and shutdown a considerable fraction of the whole network. This is the reason of cascading failure.

So a cascading failure is failure in a system of interconnected parts, where the service provided depends on the operation of a preceding part, and the failure of a preceding part can trigger the failure of successive parts. Redundant parts can lessen the impact of, but not preventa failure. When cascading failure is over, we calculate difference of network efficiency. It can be showed as formula (3):

$$
I_{k}=1-E_{k} / E_{0}
$$

$I_{k}$ is importance of a node. $E$ is average efficiency of network. $E_{0}$ is average efficiency when network operates well. $E_{k}$ is average efficiency of network after cascading failure. We normalized the value of $I_{k}$ and get the weight of each node.

The damage caused by a cascade is quantified in terms of the relative size $G$ of the largest connected component

$$
G=\frac{N^{\prime}}{N}
$$

where $N$ and $N^{\prime}$ are the numbers of nodes in the largest component before and after the cascade respectively. The integrity of the network is maintained if $G \approx 1$, while 
breakdown occurs if $G \approx 0$.

\section{A Case Study}

This is a network of food supply chain. We use this network to calculate node importance considering cascading failures.

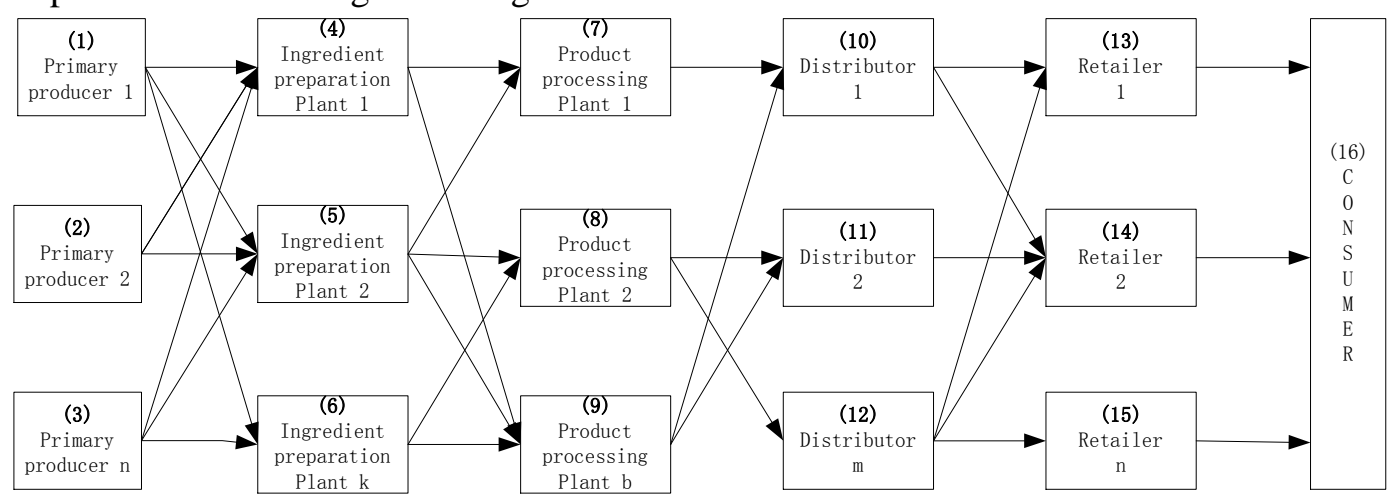

Figure 2. Food Supply Chain

This network contains 6 main links such as primary producer; ingredient preparation plant; product processing plant; distributor; retailer and consumer. The results are showing as follows:

\subsection{Density}

Density is the measurement of the proportion of actual number of arcs and the total number of possible arcs. It is an indication of how knitted a network is. In this graph, the density is 0.12 , pointing to a moderately strong degree of interconnectedness between food supply processes. This measurement, however, says little about the vulnerability of food supply network apart from providing a vague idea of food supply processes interconnectedness. For instance, it does not tell us which process is most relied upon, which is important in the study of food supply chain network. since the most relied upon process is the one that contributes most to potential cascading failure. To examine the most relied upon process, one has to use the centrality measurement.

\subsection{Degree Centrality}

Centrality is a measurement of actor prominence in a network. Often, the number of ties enjoyed by an actor indicates the importance of an actor in a particular network. The same can be said about food supply chain network. The more ties a food supply chain network has, the more involved the food supply processes is in sustaining the operation of the network. From the measurement of Degree Centrality, it appears that all of the supply processes are more or less important as shown in Table 1. The measurement indicates that each supply processes has at least two connections to other processes. The supply processes are only linked to adjacent supply processes. 
Table 1. Degree Centrality

\begin{tabular}{|c|c|c|c|c|c|c|c|}
\hline node & $\begin{array}{c}\text { Degree } \\
\text { Centrality }\end{array}$ & node & $\begin{array}{c}\text { Degree } \\
\text { Centrality }\end{array}$ & node & $\begin{array}{c}\text { Degree } \\
\text { Centrality }\end{array}$ & node & $\begin{array}{c}\text { Degree } \\
\text { Centrality }\end{array}$ \\
\hline 1 & $\mathbf{3}$ & 5 & $\mathbf{6}$ & 9 & $\mathbf{5}$ & 13 & $\mathbf{3}$ \\
\hline 2 & $\mathbf{2}$ & 6 & $\mathbf{4}$ & 10 & $\mathbf{4}$ & 14 & $\mathbf{4}$ \\
\hline 3 & $\mathbf{3}$ & 7 & $\mathbf{3}$ & 11 & $\mathbf{3}$ & 15 & $\mathbf{2}$ \\
\hline 4 & $\mathbf{5}$ & 8 & $\mathbf{4}$ & 12 & $\mathbf{4}$ & 16 & $\mathbf{3}$ \\
\hline
\end{tabular}

\subsection{Weight of Nodes}

This study calculates importance value of each node considering cascading failure. The weight of nodes are normalization of importance value.

Table 1 shows the initial load; maximum load (when $\alpha=0.3$ ) and load change of every node when one of the nodes fails. When load exceed its maximum value, it leads to cascading failure. This load value will be marked with underline and overstriking. From table 1 we can see node 4,5,6,7,8,9,10,12,13,14 may all lead to cascading failure.

When the cascading failure is over, we calculate difference of network efficiency and importance value of each node, get the ranking of every node:

Table 2 shows process of cascading failure. For example when node 4 fails, it may lead to fail of node 5 . After node 5 collapses, node $6,8,9,10,11,12,13,14$ also fail. Other nodes such as $6,7,8,9,10$ and so on will also cause 4 or 5 nodes collapse. When node 1, 2, 3, 11, 15, 16 fails, they will not lead to cascading failure. This study calculates importance value $\left(I_{k}\right)$ of each node with $E_{0}$ and $E_{k}$ and rank nodes with it. Ingredient plant 1 , Distributor 1 , and Product processing 1,b are important nodes most other nodes rely upon. If one of the nodes fails, total or partial food network will collapse. So these nodes should be pay more attention to. The weight of every node is given on the right side of the table 2 . These important nodes have heavy weight such as node 4 is the most important node whose weight is 0.14 , the second is node 10 and its weight is 0.11 . node 15 has the lightest weight . 
Table 2. Load Change of Each Node

\begin{tabular}{|c|c|c|c|c|c|c|c|c|c|c|c|c|c|c|c|c|}
\hline node & 1 & 2 & 3 & 4 & 5 & 6 & 7 & 8 & 9 & 10 & 11 & 12 & 13 & 14 & 15 & 16 \\
\hline $\begin{array}{l}\text { Initial } \\
\text { load }\end{array}$ & 0 & 0 & 0 & 7.38 & 15.849 & 6.771 & 6.510 & 17.618 & 15.871 & 15.266 & 5.423 & 12.311 & 3.960 & 6.941 & 1.099 & 0 \\
\hline $\begin{array}{c}\text { Maximum } \\
\text { load }\end{array}$ & 0 & 0 & 0 & 9.594 & 20.604 & 8.802 & 8.463 & 22.903 & 20.632 & 19.846 & 7.050 & 16.004 & 5.148 & 19.023 & 1.429 & 0 \\
\hline $\begin{array}{l}1 \text { fails } \\
\text { failed }\end{array}$ & 0 & 0 & 0 & 5.173 & 11.442 & 3.386 & 5.467 & 14.218 & 13.314 & 13.659 & 4.769 & 10.573 & 3.626 & 6.370 & 1.004 & 0 \\
\hline 2 fails & 0 & 0 & 0 & 4.414 & 8.814 & 6.771 & 5.075 & 14.549 & 13.376 & 13.394 & 4.834 & 10.771 & 3.602 & 6.370 & 1.028 & 0 \\
\hline 3 fails & 0 & 0 & 0 & 5.173 & 11.442 & 3.386 & 5.467 & 14.218 & 13.314 & 13.659 & 4.769 & 10.573 & 3.626 & 6.370 & 1.004 & 0 \\
\hline 4 fails & 0 & 0 & 0 & 0 & $\underline{21.769}$ & 8.231 & 4.050 & 19.116 & 11.834 & 11.841 & 5.002 & 13.156 & 3.494 & 6.308 & 1.198 & 0 \\
\hline 5 fails & 0 & 0 & 0 & $\underline{14.690}$ & 0 & $\underline{12.310}$ & 5.25 & 10.476 & 15.271 & 14.493 & 4.793 & 8.714 & 3.669 & 6.438 & 0.893 & 0 \\
\hline 6 fails & 0 & 0 & 0 & 8.896 & $\underline{21.104}$ & 0 & 7.296 & 12.885 & 12.819 & 14.759 & 4.507 & 9.735 & 3.721 & 6.370 & 0.9090 & 0 \\
\hline 7 fails & 0 & 0 & 0 & 5.186 & 14.257 & 7.557 & 0 & 18.884 & $\underline{21.116}$ & 10.311 & 6.376 & 13.313 & 3.210 & 6.586 & 1.204 & 0 \\
\hline 8 fails & 0 & 0 & 0 & 8.953 & 8.953 & 3.095 & 7.915 & 0 & $\underline{22.085}$ & 19.522 & 4.478 & 0 & 3.969 & 6.697 & 0.333 & 0 \\
\hline 9 fails & 0 & 0 & 0 & 8.667 & 8.667 & 0.667 & $\underline{20.000}$ & 0 & 0 & 18.000 & 0.750 & 3.250 & 4.083 & 5.333 & 0.583 & 0 \\
\hline 10 fails & 0 & 0 & 0 & 4.284 & 15.483 & 7.233 & 0 & $\underline{23.831}$ & 9.169 & 0 & $\underline{10.471}$ & $\underline{17.529}$ & 1.514 & 6.973 & $\underline{1.514}$ & 0 \\
\hline 11 fails & 0 & 0 & 0 & 6.773 & 14.392 & 5.835 & 7.559 & 15.261 & 11.180 & 18.739 & 0 & 14.261 & 4.825 & 4.825 & 1.350 & 00 \\
\hline 12 fails & 0 & 0 & 0 & 8.150 & 11.450 & 4.400 & 7.499 & $\underline{4.034}$ & 18.467 & 18.265 & $\underline{7.735}$ & 0 & 3.347 & 7.653 & 0 & 0 \\
\hline 13 fails & 0 & 0 & 0 & 6.337 & 14.415 & 6.248 & 4.425 & 16.240 & 13.335 & 8.009 & 6.389 & 9.602 & 0 & 10.403 & $\underline{1.597}$ & 0 \\
\hline 14 fails & 0 & 0 & 0 & 6.449 & 14.446 & 6.105 & 5.633 & 16.127 & 12.240 & 12.006 & 0 & 11.994 & $\underline{8.806}$ & 0 & $\underline{2.194}$ & 0 \\
\hline 15 fails & 0 & 0 & 0 & 7.457 & 13.806 & 5.736 & 6.600 & 12.292 & 16.108 & 15.513 & 5.649 & 5.838 & 4.396 & 7.604 & 0 & 0 \\
\hline 16 fails & 0 & 0 & 0 & 6.546 & 14.349 & 6.105 & 5.221 & 15.555 & 13.224 & 10.545 & 3.442 & 10.013 & 0 & 0 & 0 & 0 \\
\hline
\end{tabular}


Table 3. Weight of Every Node

\begin{tabular}{|c|l|c|c|c|c|c|}
\hline node & \multicolumn{1}{|c|}{$\begin{array}{c}\text { process of } \\
\text { cascading failure }\end{array}$} & $E_{0}$ & $E_{k}$ & $I_{k}$ & ranking & weight \\
\hline 1 & no & 0.2184 & 0.1915 & 0.1230 & 12 & 0.017 \\
\hline 2 & no & 0.2184 & 0.1915 & 0.1230 & 12 & 0.017 \\
\hline 3 & no & 0.2184 & 0.1915 & 0.1230 & 12 & 0.017 \\
\hline 4 & $4-5-6,8,9$, & 0.2184 & 0 & 1 & 1 & 0.140 \\
\hline 5 & $5-4-6$ & 0.2184 & 0.0833 & 0.6186 & 7 & 0.087 \\
\hline 6 & $6-5-4$ & 0.2184 & 0.0833 & 0.6186 & 7 & 0.087 \\
\hline 7 & $7-9-8,12,15$ & 0.2184 & 0.0583 & 0.7331 & 3 & 0.103 \\
\hline 8 & $8-9-7$ & 0.2184 & 0.0771 & 0.6470 & 6 & 0.091 \\
\hline 9 & $9-7-8,12,15$ & 0.2184 & 0.0583 & 0.7331 & 3 & 0.103 \\
\hline 10 & $10-8,11,12,15$ & 0.2184 & 0.0458 & 0.7862 & 2 & 0.110 \\
\hline 11 & no & 0.2184 & 0.1933 & 0.1148 & 15 & 0.016 \\
\hline 12 & $12-11-10$ & 0.2184 & 0.0646 & 0.7042 & 5 & 0.099 \\
\hline 13 & $13-15$ & 0.2184 & 0.1761 & 0.1938 & 10 & 0.027 \\
\hline 14 & $14-13,15$ & 0.2184 & 0.1313 & 0.3990 & 9 & 0.056 \\
\hline 15 & no & 0.2184 & 0.2021 & 0.0745 & 16 & 0.010 \\
\hline 16 & no & 0.2184 & 0.1899 & 0.1305 & 11 & 0.018 \\
\hline
\end{tabular}

\subsection{Relative Size of Largest Connected Component}

Cascading failures can be conveniently quantified by the relative size of the largest connected component $G=\frac{N^{\prime}}{N}$, where $N$ and $N^{\prime}$ are the numbers of nodes in the largest component before and after the cascade. The relative size of $G$ is different according to various attack manner. In this paper we use two kinds of attack manners: attack node with largest degree or load. Table 4 shows the degree and load of each node:

Table 4. Load and Degree of Each Node

\begin{tabular}{|c|c|c|c|c|c|c|c|c|}
\hline node & $\mathbf{1}$ & $\mathbf{2}$ & $\mathbf{3}$ & $\mathbf{4}$ & $\mathbf{5}$ & $\mathbf{6}$ & $\mathbf{7}$ & $\mathbf{8}$ \\
\hline degree & 3 & 2 & 3 & 5 & $\underline{\mathbf{6}}$ & 4 & 3 & 4 \\
\hline load & 0 & 0 & 0 & 7.38 & 15.849 & 6.771 & 6.510 & $\underline{\mathbf{1 7 . 6 1 8}}$ \\
\hline node & $\mathbf{9}$ & $\mathbf{1 0}$ & $\mathbf{1 1}$ & $\mathbf{1 2}$ & $\mathbf{1 3}$ & $\mathbf{1 4}$ & $\mathbf{1 5}$ & $\mathbf{1 6}$ \\
\hline degree & 5 & 4 & 3 & 4 & 3 & 4 & 2 & 3 \\
\hline load & 15.871 & 15.266 & 5.423 & 12.311 & 3.960 & 6.941 & 1.099 & 0 \\
\hline
\end{tabular}


Table 5. Load of Each Node

\begin{tabular}{|c|c|c|c|c|c|c|c|c|c|c|c|c|}
\hline$\underbrace{\operatorname{load}}_{\mathrm{n}} \alpha$ & 0.1 & 0.2 & 0.3 & 0.4 & 0.5 & 0.6 & 0.7 & 0.8 & 0.9 & 1 & $\begin{array}{c}5 \\
\text { fail } \\
s\end{array}$ & $\begin{array}{c}8 \\
\text { fail } \\
s\end{array}$ \\
\hline 1 & 0 & 0 & 0 & 0 & 0 & 0 & 0 & 0 & 0 & 0 & 0 & 0 \\
\hline 2 & 0 & 0 & 0 & 0 & 0 & 0 & 0 & 0 & 0 & 0 & 0 & 0 \\
\hline 3 & 0 & 0 & 0 & 0 & 0 & 0 & 0 & 0 & 0 & 0 & 0 & 0 \\
\hline 4 & 8.118 & 8.856 & 9.594 & 10.332 & 11.07 & 11.808 & 12.546 & 13.284 & 14.022 & 14.76 & $\underline{14.69}$ & 8.953 \\
\hline 5 & $\begin{array}{c}17.433 \\
9\end{array}$ & $\begin{array}{c}19.018 \\
8\end{array}$ & $\begin{array}{c}20.603 \\
7\end{array}$ & $\begin{array}{c}22.188 \\
6\end{array}$ & $\begin{array}{c}23.773 \\
5\end{array}$ & $\begin{array}{c}25.358 \\
4\end{array}$ & $\begin{array}{c}26.943 \\
3\end{array}$ & $\begin{array}{c}28.528 \\
2\end{array}$ & $\begin{array}{c}30.113 \\
1\end{array}$ & $\begin{array}{c}31.69 \\
8\end{array}$ & 0 & 8.953 \\
\hline 6 & 7.4481 & 8.1252 & 8.8023 & 9.4794 & $\begin{array}{c}10.156 \\
5\end{array}$ & $\begin{array}{c}10.833 \\
6\end{array}$ & $\begin{array}{c}11.510 \\
7\end{array}$ & $\begin{array}{c}12.187 \\
8\end{array}$ & $\begin{array}{c}12.864 \\
9\end{array}$ & $\begin{array}{c}13.54 \\
2\end{array}$ & $\underline{12.31}$ & 3.095 \\
\hline 7 & 7.161 & 7.812 & 8.463 & 9.114 & 9.765 & 10.416 & 11.067 & 11.718 & 12.369 & 13.02 & 5.25 & 7.915 \\
\hline 8 & $\begin{array}{c}19.379 \\
8\end{array}$ & $\begin{array}{c}21.141 \\
6\end{array}$ & $\begin{array}{c}22.903 \\
4\end{array}$ & $\begin{array}{c}24.665 \\
2\end{array}$ & 26.427 & $\begin{array}{c}28.188 \\
8\end{array}$ & $\begin{array}{c}29.950 \\
6\end{array}$ & $\begin{array}{c}31.712 \\
4\end{array}$ & $\begin{array}{c}33.474 \\
2\end{array}$ & $\begin{array}{c}35.23 \\
6\end{array}$ & $\begin{array}{c}10.47 \\
6\end{array}$ & 0 \\
\hline 9 & $\begin{array}{c}17.458 \\
1\end{array}$ & $\begin{array}{c}19.045 \\
2\end{array}$ & $\begin{array}{c}20.632 \\
3\end{array}$ & $\begin{array}{c}22.219 \\
4\end{array}$ & $\begin{array}{c}23.806 \\
5\end{array}$ & $\begin{array}{c}25.393 \\
6\end{array}$ & $\begin{array}{c}26.980 \\
7\end{array}$ & $\begin{array}{c}28.567 \\
8\end{array}$ & $\begin{array}{c}30.154 \\
9\end{array}$ & $\begin{array}{c}31.74 \\
2\end{array}$ & $\begin{array}{c}15.27 \\
1\end{array}$ & $\frac{22.08}{\underline{5}}$ \\
\hline 10 & $\begin{array}{c}16.792 \\
6\end{array}$ & $\begin{array}{c}18.319 \\
2\end{array}$ & $\begin{array}{c}19.845 \\
8\end{array}$ & $\begin{array}{c}21.372 \\
4\end{array}$ & 22.899 & $\begin{array}{c}24.425 \\
6\end{array}$ & $\begin{array}{c}25.952 \\
2\end{array}$ & $\begin{array}{c}27.478 \\
8\end{array}$ & $\begin{array}{c}29.005 \\
4\end{array}$ & $\begin{array}{c}30.53 \\
2\end{array}$ & $\begin{array}{c}14.49 \\
3\end{array}$ & $\begin{array}{c}19.52 \\
2\end{array}$ \\
\hline 11 & 5.9653 & 6.5076 & 7.0499 & 7.5922 & 8.1345 & 8.6768 & 9.2191 & 9.7614 & $\begin{array}{c}10.303 \\
7\end{array}$ & $\begin{array}{c}10.84 \\
6\end{array}$ & 4.793 & 4.478 \\
\hline 12 & $\begin{array}{c}13.542 \\
1\end{array}$ & $\begin{array}{c}14.773 \\
2\end{array}$ & $\begin{array}{c}16.004 \\
3\end{array}$ & $\begin{array}{c}17.235 \\
4\end{array}$ & $\begin{array}{c}18.466 \\
5\end{array}$ & $\begin{array}{c}19.697 \\
6\end{array}$ & $\begin{array}{c}20.928 \\
7\end{array}$ & $\begin{array}{c}22.159 \\
8\end{array}$ & $\begin{array}{c}23.390 \\
9\end{array}$ & $\begin{array}{c}24.62 \\
2\end{array}$ & 8.714 & 0 \\
\hline 13 & 4.356 & 4.752 & 5.148 & 5.544 & 5.94 & 6.336 & 6.732 & 7.128 & 7.524 & 7.92 & 3.669 & 3.969 \\
\hline 14 & 7.6351 & 8.3292 & 9.0233 & 9.7174 & $\begin{array}{c}10.411 \\
5\end{array}$ & $\begin{array}{c}11.105 \\
6\end{array}$ & $\begin{array}{c}11.799 \\
7\end{array}$ & $\begin{array}{c}12.493 \\
8\end{array}$ & $\begin{array}{c}13.187 \\
9\end{array}$ & $\begin{array}{c}13.88 \\
2\end{array}$ & 6.438 & 6.697 \\
\hline 15 & 1.2089 & 1.3188 & 1.4287 & 1.5386 & 1.6485 & 1.7584 & 1.8683 & 1.9782 & 2.0881 & 2.198 & 0.893 & 0.333 \\
\hline 16 & 0 & 0 & 0 & 0 & 0 & 0 & 0 & 0 & 0 & 0 & 0 & 0 \\
\hline
\end{tabular}


From this table we can see that node 5 has the largest degree and node 8 has the largest load. We assume two kinds of situations: the first is node 5 fails and other nodes operate well. Then we calculate the relative size of $G$ when $\alpha$ takes different value; the second is node 8 fails and other nodes operate well. We also calculate $G$.

Table 5 shows when $\alpha$ takes different value from 0 to 1 , the maximum load of each node. It also tells us when node 5 or 8 fails, the load change of each node. It shows that when node 5 fails, the load of 4 and 6 increase which exceed maximum load when $\alpha$ is from 0 to 0.8 . When $\alpha$ is 0.9 , node 5 only lead node 4 to fail. When $\alpha$ is 1.0 , it will not lead to cascading failure. The result is shown in table 6 . When $\alpha$ is from 0 to 0.8 , the relative size of $G$ is 0.625 . When $\alpha$ is 0.9 or 1.0 , the value of $G$ will increase to 0.875 and 0.9375 .

Table 6. Failure Process of Node 5

\begin{tabular}{|c|c|c|c|}
\hline$\alpha$ & $\begin{array}{c}\text { failure process of } \\
\text { node 5 }\end{array}$ & $N^{\prime}$ & $\mathrm{G}$ \\
\hline 0 & 5 5-4, 6 & 10 & 0.625 \\
\hline 0.1 & $5-4,6$ & 10 & 0.625 \\
\hline 0.2 & $5-4,6$ & 10 & 0.625 \\
\hline 0.3 & 5 -4, 6 & 10 & 0.625 \\
\hline 0.4 & $5-4,6$ & 10 & 0.625 \\
\hline 0.5 & $5-4,6$ & 10 & 0.625 \\
\hline 0.6 & $5-4,6$ & 10 & 0.625 \\
\hline 0.7 & $5-4,6$ & 10 & 0.625 \\
\hline 0.8 & $5-4,6$ & 10 & 0.625 \\
\hline 0.9 & $5-4$ & 14 & 0.875 \\
\hline 1.0 & 5 & 15 & 0.9375 \\
\hline
\end{tabular}

The other result is shown in table 7.When $\alpha$ is 0 and 0.1 , failure of node 8 will lead to failure of node 4,7,9,10. and the value of $G$ at this time is 0.375 . When $\alpha$ is 0.2 , node 9,7 will fail after node 8 fails and $G$ is 0.4375 . When $\alpha$ is above 0.3 , failure of node 8 will not lead to cascading failure and the relative size of $G$ is 0.9375

Table 7. Failure Process of Node 8

\begin{tabular}{|c|c|c|c|}
\hline$\alpha$ & failure process of node & $N^{\prime}$ & G \\
\hline 0 & $8-4,7,9, \quad 10$ & 6 & 0.375 \\
\hline 0.1 & $8-4,7,9,10$ & 6 & 0.375 \\
\hline 0.2 & $8-4-7$ & 7 & 0.4375 \\
\hline 0.3 & 8 & 15 & 0.9375 \\
\hline 0.4 & 8 & 15 & 0.9375 \\
\hline 0.5 & 8 & 15 & 0.9375 \\
\hline 0.6 & 8 & 15 & 0.9375 \\
\hline 0.7 & & 15 & 0.9375 \\
\hline
\end{tabular}




\begin{tabular}{|l|l|l|l|}
\hline 0.8 & 8 & 15 & 0.9375 \\
\hline 0.9 & 8 & 15 & 0.9375 \\
\hline 1.0 & 8 & 15 & 0.9375 \\
\hline
\end{tabular}

With the result of table 6 and table 7, we get the relationship of $G$ and $\alpha$ when node 5 and node 8 fail. We use a line graph to indicate the relationship between them.

This graph is relationship between the relative size $G$ and tolerance parameter $\alpha$. The solid line is value of $G$ when node 5 fails at different value of $\alpha$. The dashed line is value of $G$ when node 8 fails at different value of $\alpha$. From the graph we can see that when the values of $\alpha$ are same, the value of $G$ is lower when we attack the largest load node compared with the largest degree node. This is because usually the largest load node is more important than node with largest degree. So the damage degree is large when delete this kind of node. But when $\alpha$ is higher, the $G$ is higher when node 8 fails compared with node 5 .

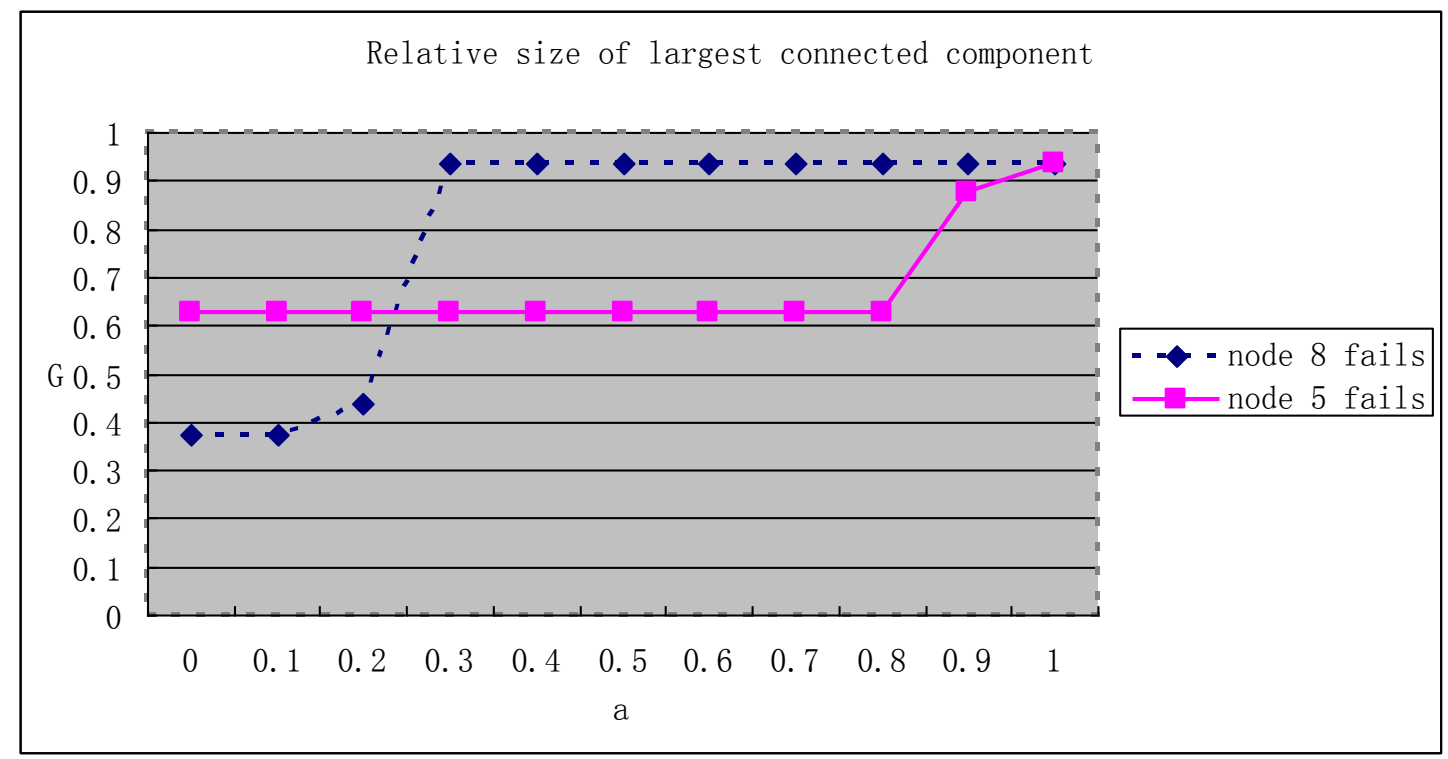

Figure 3. Relative Size of Largest Connected Component

\section{Conclusion}

Interdependency among process of food supply poses potential cascading failure of supply process. This is one of the major vulnerabilities of process of food supply. Among the interconnected supply process, some contribute more to cascading failure than others. By identifying the supply process that potentially contributes most to cascading effect, one can prioritize the protection of process of food supply.

Interdependency among supply processes give rise to the formation of food supply chain network. In this analysis, we look at one particular aspect of the food supply chain network, i.e. the key nodes that are most relied upon, thus contribute the most to supply vulnerability in terms of cascading impact. We identify Ingredient plant 1, Distributor 1, and Product processing 1, b as four critical processes that are most relied upon. However, among the four, Ingredient plant 1 is more important compares to others. The Ingredient plant 1 and Distributor 1, more than Product processing 1,b, as a result, should be given priority in our effort to protect food supply chain network, especially from cascading failures that arises out of node interdependency. We also identify that the relative size of largest connected component after the node of largest 
degree fails is higher than after the node of largest load fails when tolerance parameter is below 2.5 .

\section{Acknowledgement}

This work was supported by funds from Liaoning province for philosophy and social science of China.(201657030)

\section{References}

[1] DarrenM.Scott and DavidC.Novak, "Network Robustness Index: A new method for identifying critical links and evaluating the performance of transportation networks",Journal of Transport Geography , vol.28,no.11,(2015), pp.539- 551.

[2] A. Hills. "Insidious Environments: Creeping Dependencies and Urban Vulnerabilities", Journal of Contingencies and Crisis Management, vol.13,no.1,(2015),pp.123-133.

[3] Barabasi A L and Albert R. "Emergence of scaling in random networks", Science, vol.23,no.9,(2014),pp.509-519.

[4] Benyah Shaparenko and Rich Caruana , "Identifying Temporal Patternsand Key Players in Document Collections", Department of Computer Science, vol.74,no.3, (2015), pp.838-848.

[5] M.F. Stringer and M.N. Hall. "A generic model of the integrated food supply chain to aid the investigation of food safety breakdowns", Food Control, vol.18,no.12,(2011), pp.755-766. .

[6] Chen Y and Hu A Q, "A methodfor finding the most vital node in communication networks", High Technology Letters, vol22,no.1,(2014),pp.573-576.

[7] AdilsonE.Motter and Ying-ChengLai,. "Cascade-based attacks on complexnetworks" , Physical review E,vol.66,no.3,(2012),pp.121-135.

[8] Costa P. Nedic, Ian Dobson and Daniel S. Kirschen ,. "Criticality in a Cascading Failure Blackout Model," Electrical Power and Energy Systems, vol.28,no.4,(2016),pp.627-633.

[9] Freeman L. "A set of measures of centrality based upon betweenness",Sociometry , vol.40,no.3,(2011),pp.35-41.

[10] Hee K.Cho and ChaeY.Lee, "Multicast tree rearrangement to recover node failures in overlay multicast networks", Computers \& operations Research , vol.33,no.3, (2013),pp.581-594.

[11] H. W .CORLEY and David Y. SHA, "Most vital links and nodes in weighted networks", Department of Industrial Engineering, vol.44,no.3,(2012),pp.157-161.

[12] J. Asha and D. Newth. "Optimizing complex networks for resilience against cascading failure", Physica A, vol.180,no.4,(2012),pp.673-683.

[13] Holme and Kim, "Bounds and Information Theory" . SIAM Journal on Algorithms and Discrete Mathematics,vol.11,no.7,(1986),pp.560-570.

[14] Omar Ahumada and J. Rene Villalobos. "Application of planning models in the agri-food supply chain: A review", European Journal of Operational Research, vol.26,no.10, (2015), pp.156-165.

[15] LiangGao and JinshanZhao, "A symmetry between odd and even node weight in complex networks", Physica A, vol. 376,no.10,(2015),pp.687-691.

[16] Linton C.Freman, "A Set of Measures of Centrality Based on Betweenness,"American Sociological Association, vol.40,no.2,(2013),pp.35-41.

[17] M. E. J. Newman. "Who is the best connected scientist?A study of scientific coauthorship networks", Journal of Mathematical Sociology, vol.40, no.7,(2014), pp.679-691.

[18] B. Ilbery and D. Maye, "Retailing local food in the Scottish-English borders:A supply chain perspective",Geoforum, vol.37,no.19,(2006),pp.352-367.

[19] H.Zhao and Z.Y.Gao, "Organizations of rich nodes in complex networks",Physica A, vol.381,no.1,(2010),pp.473-481.

[20] J.J.Wu and Z.Y.Gao, " Effects of the cascading failures on scale-free traffic networks",Physica A, vol.378,no.3,(2013),pp.505-511. 


\section{Authors}

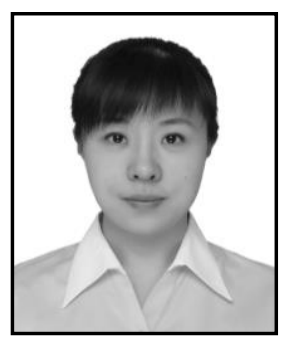

Yan Yan, She is a lecture of management department at Shenyang University of Technology. She received her PH.D in management from Northeasten University in China. Her current research interests include emergency management, resilient supply chain. 